\title{
Reduced expression of the mouse ribosomal protein Rpl17 alters the diversity of mature ribosomes by enhancing production of shortened 5.8S rRNA
}

\author{
MINSHI WANG, ${ }^{1,2}$ ANDREY V. PARSHIN, ${ }^{1}$ NATALIA SHCHERBIK, ${ }^{1}$ and DIMITRI G. PESTOV ${ }^{\mathbf{1}}$ \\ ${ }^{1}$ Department of Cell Biology, Rowan University School of Osteopathic Medicine, Stratford, New Jersey 08084, USA
}

\begin{abstract}
Processing of rRNA during ribosome assembly can proceed through alternative pathways but it is unclear whether this could affect the structure of the ribosome. Here, we demonstrate that shortage of a ribosomal protein can change pre-rRNA processing in a way that over time alters ribosome diversity in the cell. Reducing the amount of Rpl17 in mouse cells led to stalled $60 \mathrm{~S}$ subunit maturation, causing degradation of most of the synthesized precursors. A fraction of pre-60S subunits, however, were able to complete maturation, but with a $5^{\prime}$-truncated $5.8 \mathrm{~S}$ rRNA, which we named $5.8 \mathrm{~S}_{\mathrm{C}}$. The $5^{\prime}$ exoribonuclease Xrn2 is involved in the generation of both $5.8 \mathrm{~S}_{\mathrm{C}}$ and the canonical long form of $5.8 \mathrm{~S}$ rRNA. Ribosomes containing $5.8 \mathrm{~S}_{\mathrm{C}}$ rRNA are present in various mouse and human cells and engage in translation. These findings uncover a previously undescribed form of mammalian 5.8S rRNA and demonstrate that perturbations in ribosome assembly can be a source of heterogeneity in mature ribosomes.
\end{abstract}

Keywords: ribosome; ribosomal protein; ribosome biogenesis; mammalian cells; RNA processing

\section{INTRODUCTION}

Eukaryotic ribosome biogenesis is a dynamic biosynthetic process in which 4 rRNAs and $\sim 80$ ribosomal proteins ( $\mathrm{r}$-proteins) are assembled in a complex series of steps to generate small (40S) and large (60S) ribosomal subunits (Woolford and Baserga 2013; Henras et al. 2015). Incorporation of r-proteins into preribosomes in vivo follows a broadly hierarchical order, according to which these proteins can be divided into several earlier- and later-acting assembly groups (Auger-Buendia et al. 1979; Lastick 1980; Todorov et al. 1983; O'Donohue et al. 2010; Chen and Williamson 2013; Gamalinda et al. 2014). Early-binding r-proteins promote subsequent assembly steps by facilitating structural rearrangements in pre-rRNA and enabling binding of assembly factors (Ferreira-Cerca et al. 2007; Babiano and de la Cruz 2010; Jakob et al. 2012; Ohmayer et al. 2013). Studies in different species have demonstrated that lack of an essential r-protein stalls maturation of ribosomal precursors, which are then degraded by the nucleolar surveillance machinery (Moritz et al. 1990; Robledo et al. 2008; Pöll et al. 2009; Jakovljevic et al. 2012; Gamalinda et al. 2013).

\footnotetext{
${ }^{2}$ Present address: Blood Cell Development and Function Program, Fox Chase Cancer Center, Philadelphia, PA 19111-2497, USA Corresponding author: pestovdg@rowan.edu

Article published online ahead of print. Article and publication date are at http://www.rnajournal.org/cgi/doi/10.1261/rna.051169.115.
}

Whereas a complete genetic ablation of individual r-proteins leads to severe growth defects and organismal lethality, with only a few known exceptions (Kirn-Safran et al. 2007; McIntosh et al. 2011; Babiano et al. 2012; Steffen et al. 2012; O'Leary et al. 2013), their suboptimal expression often results in complex pathological phenotypes. In humans, reduced expression or partial loss of function in a number of r-proteins are associated with a group of congenital disorders termed ribosomopathies, characterized by impaired proliferation and increased cell death in hematopoietic progenitors and certain other cell lineages (Ellis and Gleizes 2011; Raiser et al. 2014). On a subcellular level, defects in ribosome biogenesis lead to reduced protein synthesis capacity and misregulated translational controls (Horos et al. 2012; Teng et al. 2013; Ludwig et al. 2014). In addition, perturbations in ribosome biogenesis can activate the tumor suppressor p53, triggering lineage-specific cell cycle arrest or apoptosis (for review, see Bursac et al. 2014). Although these are fairly consistent molecular consequences of defects in ribosome biogenesis, the clinical manifestations of ribosomopathies are far from uniform (Armistead and Triggs-Raine 2014). The reasons for the phenotypical variability of r-protein

(c) 2015 Wang et al. This article is distributed exclusively by the RNA Society for the first 12 months after the full-issue publication date (see http://rnajournal.cshlp.org/site/misc/terms.xhtml). After 12 months, it is available under a Creative Commons License (Attribution-NonCommercial 4.0 International), as described at http://creativecommons.org/licenses/ by-nc/4.0/. 
deficiencies are only partially understood. Current hypotheses proposed to explain this phenomenon include extra-ribosomal functions of r-proteins, association of nonribosomal regulatory proteins with preribosomes, and the synthesis of specialized ribosomes with an altered r-protein composition (Kondrashov et al. 2011; Thapa et al. 2013).

Studies over several decades, particularly in animal cells, have shown that processing of pre-rRNA during eukaryotic ribosome maturation can occur through parallel and alternative pathways (Dudov et al. 1978; Bowman et al. 1981; Hadjiolova et al. 1993; Sloan et al. 2013; Henras et al. 2015). Both physiological stimuli and experimentally induced deficiencies in factors required for ribosome biogenesis can alter the kinetics of individual processing steps, changing the relative contribution of different pathways (Savino and Gerbi 1990; Lapik et al. 2004; Wang et al. 2014). An outstanding question raised by these observations is whether different routes in preribosome maturation always converge to yield a singular kind of ribosomes or may lead to ribosomes with nonidentical structural and functional properties. In the study presented here, we used mouse cells to analyze depletion of the r-protein L17 (also known as uL22) that has an essential role in ribosome architecture and function. L17/uL22 interacts with all six secondary structure domains in $28 \mathrm{~S}$ rRNA and with 5.8S rRNA (Ben-Shem et al. 2011; Gamalinda et al. 2014), and is thought to stabilize long-range interactions important for establishing the structure of the polypeptide exit tunnel during 60S subunit assembly (Gamalinda et al. 2013). As shown below, Rpl17 deficiency in mouse cells resulted in marked changes in the way the $5^{\prime}$ end of the $32 S$ pre-rRNA is generated, and caused instability of this precursor. Significantly, degradation of pre-rRNA intermediates was not the only outcome of the aberrant ribosome biosynthesis that we observed. A fraction of pre-60S subunits were able to successfully compete for the residual Rpl17 present in the cell and complete maturation. Such subunits, however, possessed a shortened form of 5.8S rRNA, which we termed $5.8 \mathrm{~S}_{\mathrm{C}}$. We further show that this rRNA exists as a minor $5.8 \mathrm{~S}$ form in unstressed mouse and human cell lines and is present in translating polysomes. The structural implications of the newly discovered $5^{\prime}$ end heterogeneity in mammalian 5.8S rRNA are discussed. siRNAs.

\section{RESULTS AND DISCUSSION}

\section{Rpl17 is required for pre-rRNA processing in two internal transcribed spacers}

Previous biochemical studies in yeast indicated that the essential r-protein L17 belongs to a "middle-acting" group of r-proteins necessary for processing of 5.8S/25S rRNA and recruitment of ribosome assembly factors required for late stages of 60S subunit maturation (Gamalinda et al. 2013, 2014). To address the role of Rpl17 in pre-rRNA processing in a mammalian system, we established stable 3T3 cell lines carrying doxycycline-inducible Rpl17 shRNA. Consistent with a role in $60 \mathrm{~S}$ biogenesis, depletion of mouse Rpl17 led to diminished 60S subunit levels and a reduction in translating polysomes (Fig. 1A, top). To identify the stages in $60 \mathrm{~S}$

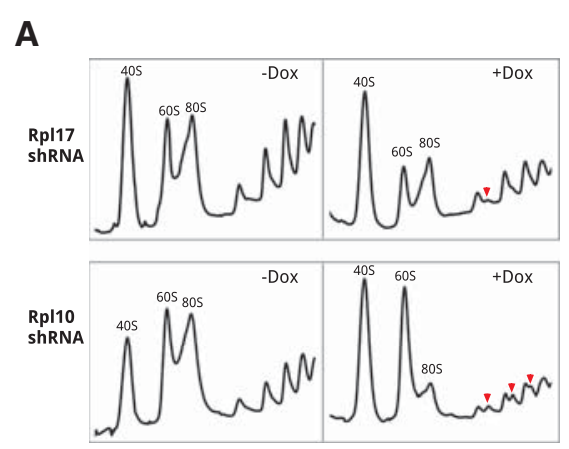

B
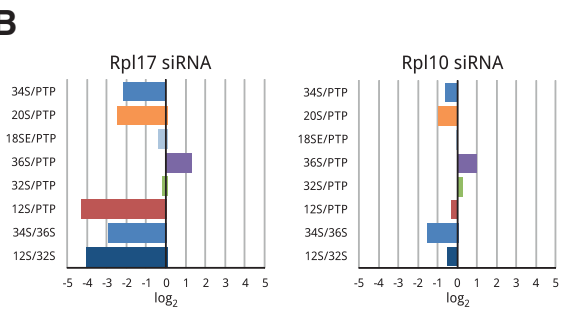

C
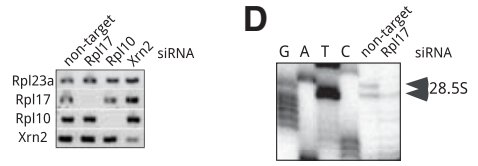

E

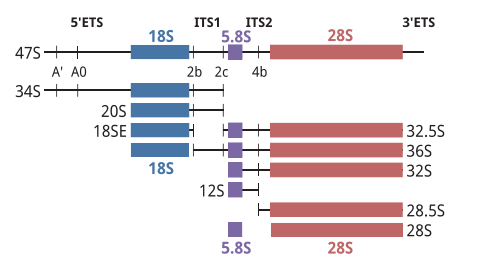

$\mathbf{F}$
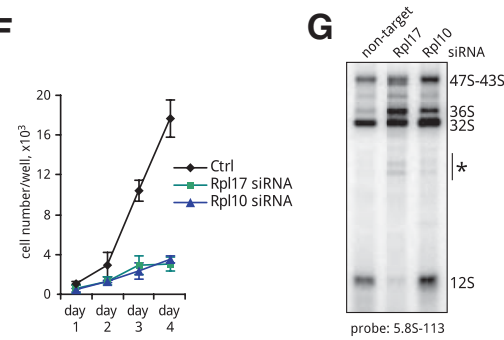

FIGURE 1. Effects of Rpl17 and Rpl10 knockdowns on translation and ribosome biogenesis. $(A)$ Depletion of Rpl17 and Rpl10 results in distinct alterations in polysome profiles. Cells stably transfected with doxycycline-inducible shRNAs against Rpl17 and Rpl10 were treated with doxycycline for $48 \mathrm{~h}$ or remained untreated (+Dox, - Dox). Cell lysates were centrifuged through $10 \%-45 \%(\mathrm{w} / \mathrm{w})$ sucrose gradients and fractionated with the continuous measurement of absorbance at $254 \mathrm{~nm}$. Halfmers are marked with red arrowheads. (B) RAMP profiles of Rpl17 and Rpl10 knockdowns showing changes in steady-state levels of pre-rRNA intermediates $48 \mathrm{~h}$ after siRNA transfections. Total cellular RNA was extracted and analyzed by northern hybridizations, ratios of various rRNA intermediates in knockdowns were normalized to the corresponding ratios in control cells transfected with nontargeting siRNA (i.e., $\log _{2}=0$ indicates no change relative to control cells; see Wang et al. [2014] for further details on this assay). (PTP) Primary transcript plus, early 47-45S pre-rRNAs. (C) RT-PCR analysis of Rpl17, Rpl10, and Xrn2 knockdowns; Rpl23a was used as a reference gene. (D) Primer extension to examine levels of $28.5 \mathrm{~S}$ prerRNA, a short-lived product of ITS2 cleavage at site $4 \mathrm{~b}$. (E) Schematic representation of the mouse $47 \mathrm{~S}$ pre-rRNA transcript with cleavage sites and major pre-rRNA processing intermediates indicated. (ETS) External transcribed spacer; (ITS) internal transcribed spacer. $(F)$ Knockdown of Rpl17 or Rpl10 severely inhibits cell proliferation. Cells were transfected with nontargeting siRNA (Ctrl), or siRNAs against Rpl17 and Rpl10 siRNA. Cell numbers were determined in triplicate transfections; error bars indicate SD. $(G)$ Depletion of Rpl17 and Rpl10 results in altered $36 \mathrm{~S}$ and $12 \mathrm{~S}$ pre-rRNA levels and accumulation of pre-rRNA decay products (asterisk). Total RNA was analyzed by a northern hybridization at $48 \mathrm{~h}$ after transfection with the indicated 
subunit maturation affected by Rpl17 depletion, we examined relative levels of various rRNA processing intermediates using the ratio analysis of multiple precursors (RAMP) (Wang et al. 2014) in cells transfected with gene-specific siRNAs (Fig. 1C). To generate a RAMP profile for Rpll7 knockdown, we normalized pre-rRNA ratios in cells transfected with siRNA targeting Rpl17 to the corresponding ratios in cells transfected with nontargeting siRNA. The observed alterations in pre-rRNA ratios (Fig. 1B, left) indicated impaired pre-rRNA processing in internal transcribed spacers 1 and 2 (ITS1 and ITS2). First, ratios of pre-rRNAs to PTP ("primary transcript plus," the combined early 47S45 S pre-rRNAs) (Wang et al. 2014) showed lowered levels of $34 \mathrm{~S}$ and $20 \mathrm{~S}$ pre-rRNAs, which are generated through cleavage at site $2 \mathrm{c}$ in ITS1 (Fig. 1E), whereas 18SE and 36S pre-rRNAs, which require site $2 \mathrm{~b}$ cleavage in ITS1, were only weakly affected or increased (Fig. 1B). This indicated that Rpl17 deficiency inhibited ITS1 cleavage at the 5.8Sproximal site $2 \mathrm{c}$, forcing the splitting of the pre-rRNA transcript through site $2 \mathrm{~b}$, similar to other previously studied 60 S synthesis factors (Wang et al. 2014). Second, the strongly reduced $12 \mathrm{~S} / \mathrm{PTP}$ and $12 \mathrm{~S} / 32 \mathrm{~S}$ ratios (Fig. 1B) suggested that Rpl17 deficiency also inhibited cleavage at site $4 \mathrm{~b}$ within ITS2, the spacer that separates $5.8 \mathrm{~S}$ and $28 \mathrm{~S}$ rRNAs. Primer extension analysis corroborated this result by showing that the $3^{\prime}$ product of site $4 \mathrm{~b}$ cleavage, $28.5 \mathrm{~S}$ pre-rRNA, was decreased in Rpl17-depleted cells (Fig. 1D).

Defects in pre-rRNA processing caused by deficiency in an $r$-protein may result not only from the protein's direct involvement in ribosome assembly, but also from translational inhibition of the synthesis of other ribosomal components and/or slower recycling of ribosome assembly factors. To address this possibility, we analyzed depletion of another essential r-protein, Rpl10 (uL16). Unlike Rpl17, Rpl10 is incorporated into nascent $60 \mathrm{~S}$ subunits after their cytoplasmic export, as shown by previous studies in both mammalian cells (Auger-Buendia et al. 1979; Lastick 1980) and yeast (Saveanu et al. 2003; West et al. 2005; Ohmayer et al. 2013). Depletion of Rpl10 severely inhibited cell growth, as did depletion of Rpl17 (Fig. 1F); however, 60S subunit levels were not significantly reduced in Rpl10-depleted cells (Fig. 1A). Instead, the gradient analysis of cytoplasmic ribosomes revealed an increase in free subunits, while the amount of translating ribosomes was greatly reduced. In addition, prominent halfmer peaks, indicative of polyribosomes containing an extra $40 \mathrm{~S}$ subunit were observed (Fig. 1A, bottom), consistent with an essential role of Rpl10 in subunit joining during translation (Eisinger et al. 1997). RAMP profiling of the Rpl10 knockdown showed changes in rRNA precursors that were much less pronounced in comparison with Rpl17 knockdown (Fig. 1B), but nevertheless they also pointed to a slightly reduced frequency of pre-rRNA splitting at site 2 c. Because Rpl10 is recruited at a late cytoplasmic step of ribosome maturation and not expected to play a direct role in pre-rRNA processing, the observed mild effects on ITS1 cleavage may be due to negative feedback from late stages of ribosome maturation and/or translation. In contrast to Rpl17, Rpl10 depletion did not alter significantly the 12S/ PTP and $12 \mathrm{~S} / 32 \mathrm{~S}$ ratios, indicating normal ITS2 processing (Fig. 1B).

The combined data from the Rpl17 and Rpl10 knockdowns lead us to conclude that Rpl17 is required for processing of the $32 \mathrm{~S}$ pre-rRNA to $28 \mathrm{~S}$ and $5.8 \mathrm{~S}$ precursors during pre-60S subunit assembly in mouse cells. This function of mammalian Rpl17 in the context of assembly parallels the function of yeast L17 (Gamalinda et al. 2013). The mouse $32 \mathrm{~S}$ pre-rRNA, however, did not significantly accumulate in Rpl17-depleted cells, as evidenced by the lack of increase in the 32S/PTP ratio (Fig. 1B). Northern hybridizations revealed an elevated amount of pre-rRNA degradation products after Rpl17 knockdown (Fig. 1G), indicating active turnover of $32 \mathrm{~S}$ pre-rRNA in pre-60S complexes. In addition to the abortive maturation of $32 \mathrm{~S}$ pre-rRNA, earlier cleavage at site $2 \mathrm{c}$ was affected to a higher extent than what can be attributed to translational inhibition, indicating that Rpl17 assembly also promotes the splitting of the pre-rRNA transcript through the 5.8S-proximal site $2 \mathrm{c}$ in ITS1.

\section{Rpl17 deficiency alters $5^{\prime}$ end processing of 5.8S rRNA precursors}

In previously studied eukaryotic species, $5.8 \mathrm{~S}$ rRNA was found to exist in two forms, long and short, which in yeast result from the use of alternative processing pathways (Henry et al. 1994). The major short form of mammalian $5.8 \mathrm{~S}$ rRNA, $5.8 \mathrm{~S}_{\mathrm{S}}$, exhibits a one-nucleotide heterogeneity of its $5^{\prime}$ ends, as illustrated in Figure 2A, while the less abundant long species $5.8 \mathrm{~S}_{\mathrm{L}}$ has a 5-6-nucleotide $5^{\prime}$ extension. As the above results show, $32 \mathrm{~S}$ pre-rRNA is the last $5.8 \mathrm{~S} / 28 \mathrm{~S}$ precursor that can be formed in Rpl17-depleted mouse cells. Our attempts to examine $32 \mathrm{~S}$ pre-rRNA by primer extensions were initially hampered by a failure of reverse transcriptases to extend ITS2-specific primers beyond a strong GC-rich hairpin formed in $5.8 \mathrm{~S}$ rRNA, whereas primers hybridizing upstream of this structure primarily extended the abundant mature 5.8S rRNA. To circumvent this problem, we separated large pre-rRNAs from 5.8S rRNA by electrophoresis in guanidine thiocyanate-containing agarose gels (Goda and Minton 1995). Guanidine thiocyanate efficiently denatures RNA without introducing chemical modifications into RNA molecules and allows recovery of RNA suitable for primer extensions. Primer extension with $32 \mathrm{~S}$ pre-rRNA (Fig. 2B, lane 1) revealed a doublet of stops that matched the $5^{\prime}$ ends of the major short form of mammalian $5.8 \mathrm{~S}$ rRNA (Fig. 2A) and a 5-6-nt extended species; the corresponding pre-rRNAs were designated $32 \mathrm{~S}_{\mathrm{S}}$ and $32 \mathrm{~S}_{\mathrm{L}}$, respectively. Depletion of Rpl17 greatly reduced $32 \mathrm{~S}_{\mathrm{S}}$ pre-rRNA and increased $32 \mathrm{~S}_{\mathrm{L}}$ pre-rRNA (Fig. 2B, lane 2). Thus, the major short $5^{\prime}$ ends of 5.8S rRNA could not be formed and/or $32 S_{S}$ pre-rRNA was rapidly degraded when Rpl17 was 
A

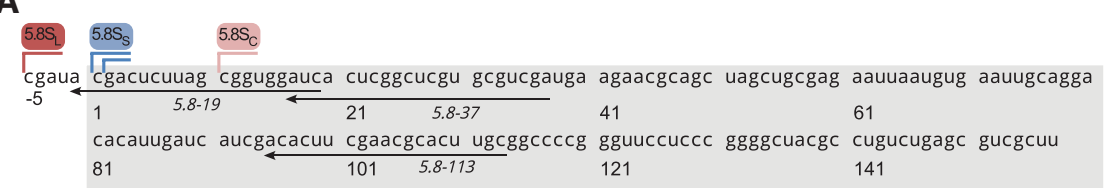

B

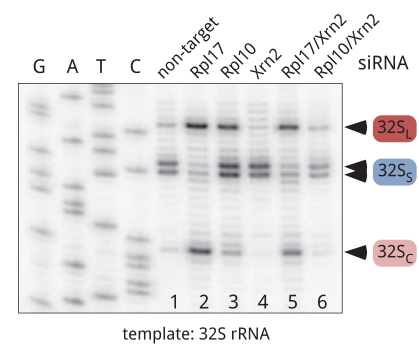

D

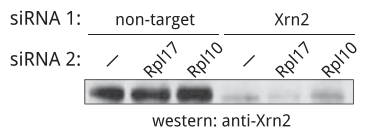

E

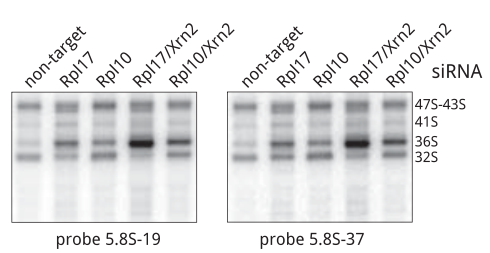

$\mathbf{F}$
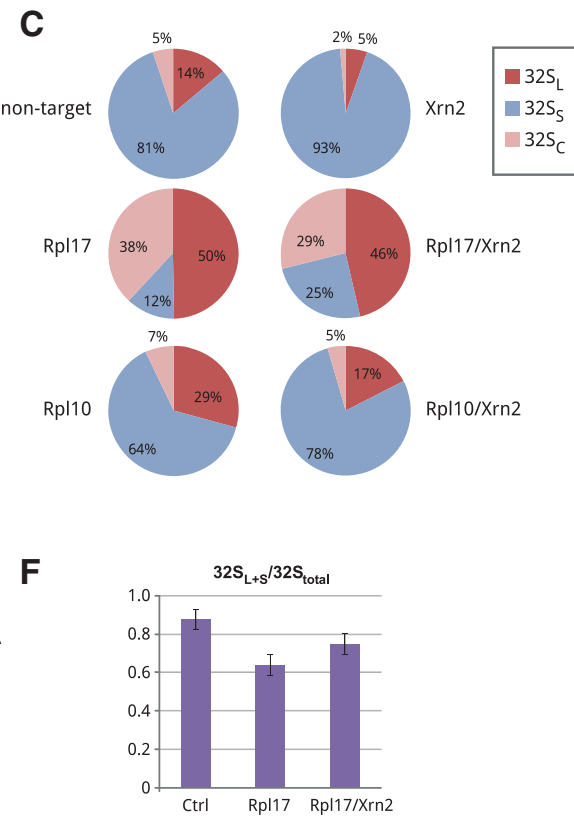

FIGURE 2. Analysis of the $5^{\prime}$ end formation in mouse $32 S$ pre-rRNA. (A) Nucleotide sequence of the mature short 5.8 $\mathrm{S}_{\mathrm{S}}$ rRNA in the mouse (boxed) and positions of $5^{\prime}$ ends of the long, short, and cropped forms $\left(5.8 \mathrm{~S}_{\mathrm{L}}, 5.8 \mathrm{~S}_{\mathrm{S}}\right.$, and $\left.5.8 \mathrm{~S}_{\mathrm{C}}\right)$. Positions of oligonucleotides used in hybridizations and primer extensions are indicated. (B) Primer extension analysis of the $5^{\prime}$ ends of gel-purified $32 \mathrm{~S}$ pre-rRNA using primer 5.8S-113. Cells were analyzed $48 \mathrm{~h}$ after transfections with the indicated siRNAs. (C) Intensities of primer extension stops corresponding to $32 \mathrm{~S}_{\mathrm{L}}, 32 \mathrm{~S}_{\mathrm{S}}$, and $32 \mathrm{~S}_{\mathrm{C}}$ prerRNAs shown in $B$ were quantified by phosphorimaging analysis and expressed as a percentage of the total $\left(32 \mathrm{~S}_{\mathrm{L}}+{ }_{\mathrm{S}}{ }_{\mathrm{C}}\right)$. (D) Immunoblotting analysis of Xrn2 levels in cells transfected with the indicated siRNA combinations. (E) Northern hybridizations of the RNA samples used for primer extensions in $B$. RNA was separated on a formaldehyde-agarose gel, blotted and hybridized with the indicated probes. Probe 5.8S-19 overlaps with site $\mathrm{C}$ (see $A$ ) and does not hybridize with $32 \mathrm{~S}_{\mathrm{C}}$, while probe $5.8 \mathrm{~S}-37$ detects all three $32 \mathrm{~S}$ forms $\left(32 \mathrm{~S}_{\mathrm{L}}, 32 \mathrm{~S}_{\mathrm{S}}\right.$, and $\left.32 \mathrm{~S}_{\mathrm{C}}\right)$. $(F)$ Quantification of $32 \mathrm{~S}_{\mathrm{L}}+_{\mathrm{S}}$ forms relative to total $32 \mathrm{~S}$ pre-rRNA from hybridizations with two $5.8 \mathrm{~S}$ probes, as shown in $E$. Data are mean values from three independent transfections with the indicated siRNAs. Error bars, SEM; see Materials and Methods for details.

limiting, while the long precursors continued to be generated. Strikingly, a prominent stop located 9-10 nt downstream from the $5^{\prime}$ end of $32 S_{S}$ rRNA was observed after Rpl17 depletion (Fig. 2B, lane 2); for consistency with other truncated mammalian processing intermediates (Carron et al. 2011; Preti et al. 2013), this RNA species was designated $32 \mathrm{~S}_{\mathrm{C}}$ ("cropped"). The $32 \mathrm{~S}_{\mathrm{C}}$ pre-rRNA was also detectable at low levels in cells transfected with nontargeting siRNA (Fig. 2B, lane 1). Quantification of primer extension stops (Fig. 2C) showed that under normal conditions, $\sim 80 \%$ of $32 \mathrm{~S}$ prerRNA was comprised of the $32 \mathrm{~S}_{\mathrm{S}}$ form, whereas in Rpl17-depleted cells $32 \mathrm{~S}_{\mathrm{S}}$ was greatly decreased and the $32 \mathrm{~S}_{\mathrm{L}}$ and $32 \mathrm{~S}_{\mathrm{C}}$ forms together accounted for $>80 \% 32 \mathrm{~S}$ pre-rRNA. A significant accumulation of the $32 \mathrm{~S}_{\mathrm{C}}$ form was observed in Rpl17depleted cells, but not after Rpl10 depletion (Fig. 2B, lane 3;
Fig. 2C). Interestingly, the $32 \mathrm{~S}_{\mathrm{L}}$ fraction increased moderately in Rpl10-depleted cells relative to cells transfected with nontargeting siRNA (Fig. 2C), suggesting that functional defects in ribosomes caused by lack of this late assembling protein can feed back to affect earlier processing steps at the $5^{\prime}$ end of 5.8S rRNA to some extent.

The results obtained through primer extensions revealed both similarities and differences between mouse and yeast cells with respect to the formation of $5.8 \mathrm{~S}$ rRNA precursors after L17 depletion. A $5^{\prime}$-truncated species analogous to $32 \mathrm{~S}_{\mathrm{C}}$ was observed in L17-depleted yeast (Sahasranaman et al. 2011; Gamalinda et al. 2013). Levels of 27SB precursors, equivalent to mammalian $32 \mathrm{~S}$ prerRNAs, were reported to increase in yeast after $\mathrm{L} 17$ depletion, with $27 \mathrm{SB}_{\mathrm{S}}$ increasing more than $27 \mathrm{SB}_{\mathrm{L}}$ pre-rRNA (Sahasranaman et al. 2011). In contrast, levels of the mouse $32 \mathrm{~S}_{\mathrm{S}}$ pre-rRNA showed a strong reduction after Rpl17 depletion, suggesting that either the formation of the major short ends of 5.8S rRNA in mouse cells cannot be accomplished without Rpl17 assembly or the $32 \mathrm{~S}_{\mathrm{S}}$ pre-rRNA is selectively destabilized.

\section{Role of Xrn2 in the formation of the $5^{\prime}$ ends of $5.8 \mathrm{~S}$ precursors}

The exonuclease Xrn2 mediates trimming and proofreading of $5^{\prime}$ extensions resulting from cleavages in the spacers of the mammalian pre-rRNA transcript (Wang and Pestov 2011; Preti et al. 2013; Sloan et al. 2013). To understand the role that Xrn2 plays in the formation of the different $5^{\prime}$ ends of $5.8 \mathrm{~S}$ precursors, we transfected cells with Xrn2 siRNA (Fig. 2D) and examined gel-purified 32S pre-rRNA by primer extensions (Fig. 2B, lanes 4-6). Quantification of stop intensities (Fig. 2C) showed that Xrn2 depletion increased the ratio of $32 \mathrm{~S}_{\mathrm{S}}$ pre-rRNA to $32 \mathrm{~S}_{\mathrm{L}}$ and $32 \mathrm{~S}_{\mathrm{C}}$ prerRNAs; this trend also held for Xrn2 knockdowns in cells depleted of Rpl17 and Rpl10. Thus, the long and cropped forms of $32 \mathrm{~S}$ pre-rRNA are more sensitive to cellular Xrn2 levels than the short form. Interestingly, inactivation of the Xrn2 homolog Rat1 in yeast cells affects short $5.8 \mathrm{~S}$ precursors to a larger extent than the long forms (Henry et al. 1994; El Hage et al. 2008). While formation of short $5.8 \mathrm{~S}$ precursors in yeast requires an exonuclease, long forms are thought to be generated by a direct endonucleolytic cleavage at the $\mathrm{B}_{1 \mathrm{~L}}$ 
site (Faber et al. 2006). Rat1 also promotes turnover of prerRNA in L17-depleted yeast cells by removing 10 nt from the $5^{\prime}$ end of the $27 \mathrm{SB}$ precursor, suggesting that L17 may act as a steric inhibitor limiting $5^{\prime}$ exonuclease progression (Sahasranaman et al. 2011). In agreement with this model, our primer extensions showed a decrease in the $32 \mathrm{~S}_{\mathrm{C}}$ fraction when Xrn2 was depleted in addition to Rpl17 (Fig. 2C). Therefore, the activity of Xrn 2 in the mammalian complexes that lack Rpl17 may be similar to that of Rat1 in yeast. To corroborate primer extension data, we estimated the combined amount of the $32 \mathrm{~S}_{\mathrm{L}+\mathrm{S}}$ forms in the total $32 \mathrm{~S}$ pre-rRNA using northern hybridizations with different $5.8 \mathrm{~S}$ probes (Fig. $2 \mathrm{E}$ ). Quantification of band intensities showed that Rpl17 depletion decreased the fraction contributed by the long and short forms, and Xrn2 codepletion partially counteracted this effect (Fig. 2F).

Collectively, these data indicate that Xrn2 promotes the accumulation of the $32 \mathrm{~S}_{\mathrm{L}}$ and $32 \mathrm{~S}_{\mathrm{C}}$ pre-rRNAs in mouse cells. It is currently unclear if the mammalian short $32 \mathrm{~S}_{\mathrm{S}}$ form may be generated through a distinct endonucleolytic mechanism, as postulated for the long form of yeast 27SB pre-rRNA. An endonucleolytic cleavage generating $32 \mathrm{~S}_{\mathrm{S}}$ pre-rRNA would yield a $5^{\prime}$ product with an ITS1 fragment extending all the way to the $5.8 \mathrm{~S}$ sequence. Such species were reported in early studies of mammalian pre-rRNA processing (Bowman et al. 1983), but are not readily detectable in 3T3 cells in our hands. We cannot exclude that these intermediates have a very short life span owing to their rapid $3^{\prime}$ trimming by exonucleases. Alternatively, all three $5^{\prime}$ ends in 32 S pre-rRNA might be generated through a $5^{\prime}$ exonucleolytic mechanism, in which the precise position where the nuclease terminates is determined by the state of the local structure in pre-60S complexes at the time of nuclease action.

\section{Cropped 32S precursors are processed into functional $5.8 \mathrm{~S}_{\mathrm{C}}$ rRNA}

The unexpected complexity of the $5^{\prime}$ end formation in $32 \mathrm{~S}$ pre-rRNA led us to investigate $5^{\prime}$ ends in mature $5.8 \mathrm{~S}$ rRNA. Primer extensions with gel-purified 5.8S rRNA revealed a stop that matched the $5^{\prime}$ end of $32 \mathrm{~S}_{\mathrm{C}}$ pre-rRNA (Fig. 3A). Although the existence of two $5.8 \mathrm{~S}$ forms $\left(5.8 \mathrm{~S}_{\mathrm{S}}\right.$ and $5.8 \mathrm{~S}_{\mathrm{L}}$ ) in eukaryotes has been long recognized (Rubin 1974; Smith et al. 1984), this result suggested that a fraction of mature $5.8 \mathrm{~S}$ rRNA might be derived from $32 \mathrm{~S}_{\mathrm{C}}$ pre-rRNA. To verify that the stop corresponding to the $5^{\prime}$ end of $5.8 \mathrm{~S}_{\mathrm{C}}$ rRNA was not an artefact of primer extension, we performed northern hybridizations (Fig. 3B) with probes complementary to different parts of 5.8S rRNA (Fig. 2A). Indeed, a band of a $5^{\prime}$-truncated $5.8 \mathrm{~S}$ species was detectable (Fig. 3B) with probes hybridizing downstream from the $5^{\prime}$ end of $5.8 \mathrm{~S}_{\mathrm{C}}$ rRNA, but not with probe 5.8S-19 that overlaps the $5^{\prime}$ end of this rRNA. We also reasoned that if the $5.8 \mathrm{~S}_{\mathrm{C}}$ rRNA is generated from $32 S_{C}$ pre-rRNA, increasing the frequency of
A

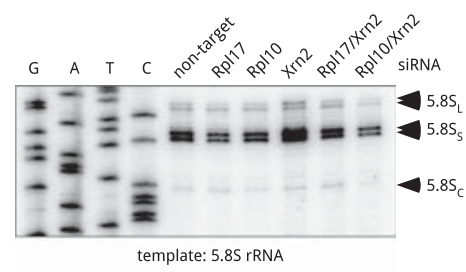

B

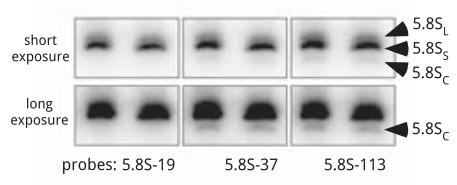

C

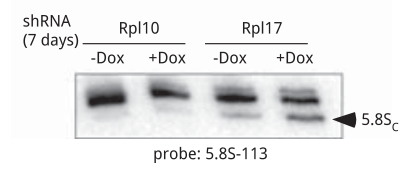

D

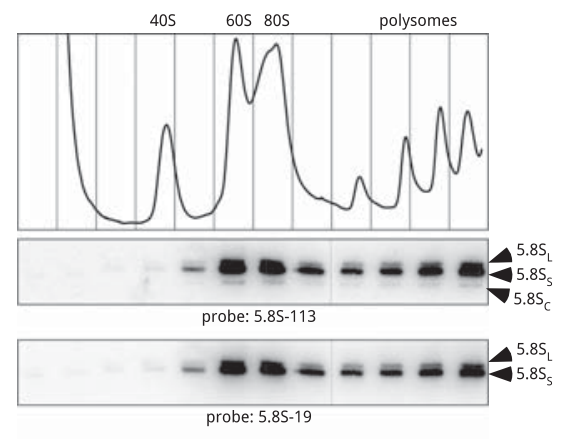

E

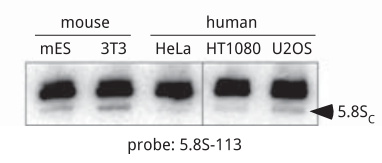

FIGURE 3. Heterogeneity of 5.8S rRNA in ribosomes from mouse and human cells. (A) Primer extension analysis of the $5^{\prime}$ ends of gel-purified $5.8 \mathrm{~S}$ rRNA using primer 5.8S-113. Cells were analyzed $48 \mathrm{~h}$ after transfections with the indicated siRNAs. $(B)$ A shortened form of $5.8 \mathrm{~S}$ rRNA is detectable by northern hybridizations. Duplicate samples of RNA from growing 3T3 cells were resolved on a polyacrylamide/urea gel, transferred to a nylon membrane and hybridized with the indicated probes. Probes 5.8S-37 and 5.8S-113 detect all three forms of 5.8S, whereas 5.8S-19 does not hybridize with $5.8 \mathrm{~S}_{C}$; see Figure 2A for probe positions. $(C)$ Prolonged depletion of Rpl17, but not Rpl10, increases the amount of 5.8S $\mathrm{S}_{\mathrm{C}} \mathrm{rRNA}_{\text {in }}$ mouse cells. Cells harboring doxycycline-inducible shRNAs were incubated with doxycycline for $7 \mathrm{~d}$ or remained untreated (+Dox, - Dox). RNA from these cells was separated by polyacrylamide gel electrophoresis and analyzed by Northern blotting. $(D) 5.8 \mathrm{~S}_{\mathrm{C}}$ rRNA is incorporated into ribosomes that are translationally competent. Growing 3T3 cells were lysed and cytoplasmic ribosomes were separated by centrifugation through $10 \%-45 \%$ (w/w) sucrose gradients. The absorbance profile of the gradient at $254 \mathrm{~nm}$ is shown at the top. RNA isolated from each gradient fraction was analyzed by polyacrylamide gel electrophoresis and northern hybridizations with probes that either detect (5.8S-113) or do not detect $(5.8 \mathrm{~S}-19)$ the $5.8 \mathrm{~S}_{\mathrm{C}}$ isoform. $(E) 5.8 \mathrm{~S}_{\mathrm{C}}$ rRNA is formed in different mouse and human cell lines. RNA was extracted from the indicated mouse and human cell lines, and analyzed as in $C$. (mES) Mouse embryonic stem cells. 
$32 \mathrm{~S}_{\mathrm{C}}$ formation should increase the fraction of $5.8 \mathrm{~S}_{\mathrm{C}}$ rRNA in the cell. Because of the long half-life of rRNA present in mature ribosomes, changes in cellular 5.8S rRNA may not become evident after short-term r-protein depletion. To allow sufficient time for the pre-existing $60 \mathrm{~S}$ subunits to turn
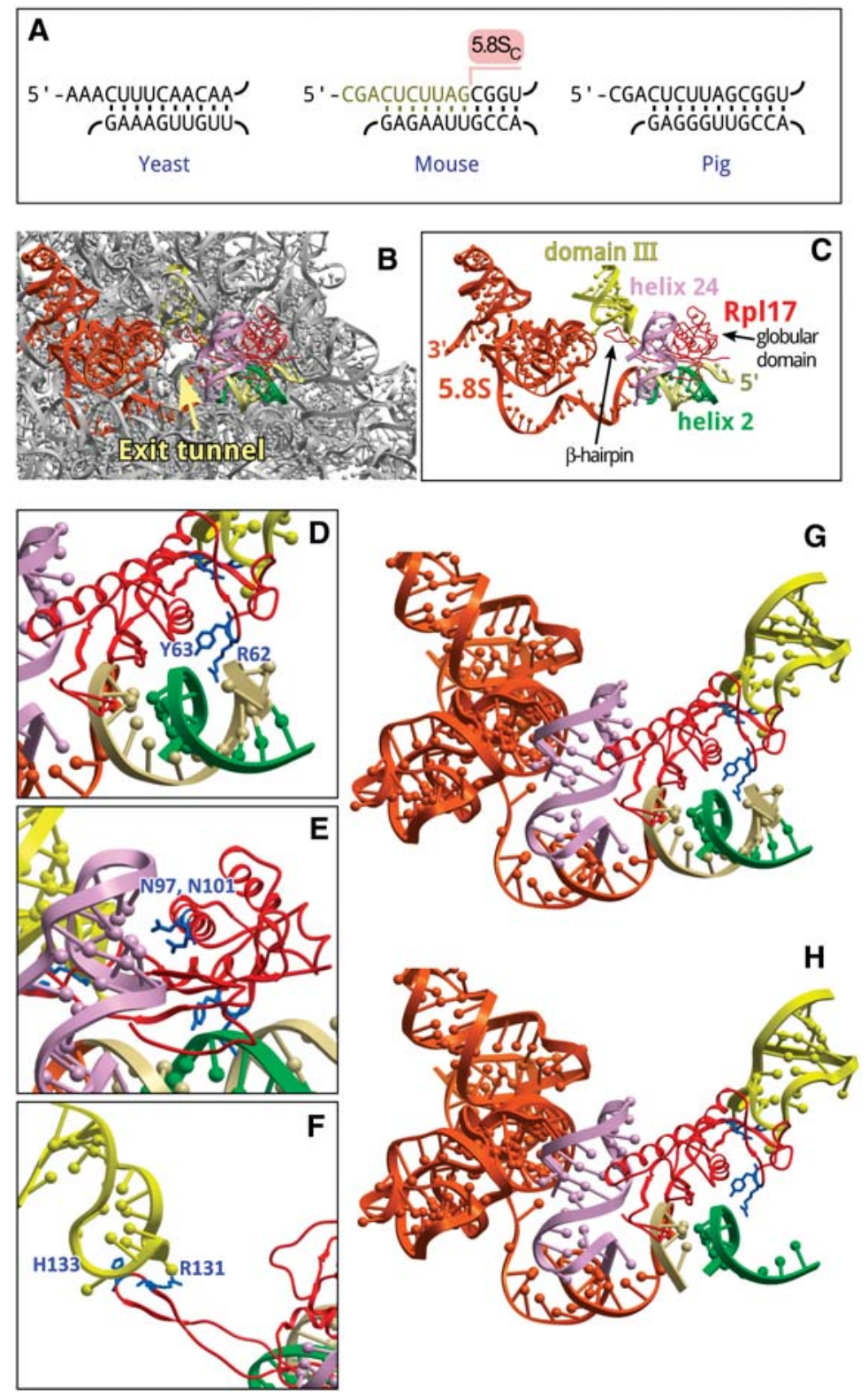

FIGURE 4. Structural implications of the $5^{\prime}$ truncation in $5.8 \mathrm{~S}$ rRNA. (A) Conservation of helix 2 in the large subunit rRNA of Saccharomyces cerevisiae, Mus musculus, and Sus scrofa. Top strand, $5.8 \mathrm{~S}_{\mathrm{S}} \mathrm{rRNA}$; bottom strand, $25 / 28 \mathrm{~S}$ rRNA. Ten nucleotides missing in $5.8 \mathrm{~S}_{\mathrm{C}} \mathrm{rRNA}$ are indicated in the mouse sequence. $(B)$ Position of 5.8S rRNA, helix 2 and Rpl17/uL22 relative to the exit tunnel in the 60 S subunit of S. scrofa (PDB: 3J71). (C) The same view showing only structural elements that surround the exit tunnel and interact with Rpl17 (red). Orange, 5.8S rRNA, the first $14 \mathrm{nu}$ cleotides at the $5^{\prime}$ terminus shown in beige. Green, helix 2, domain I (28S rRNA nucleotides 419 430, 5' -accguuaagag- $3^{\prime}$ ); light purple, helix 24 , domain I (28S rRNA nucleotides 388-410, $5^{\prime}$ aacuuugaagagagaguucaaga- $3^{\prime}$ ); yellow, domain III hairpin loop (28S rRNA nucleotides 1587$1606,5^{\prime}$-guccugacgugcaaaucggu- $\left.3^{\prime}\right)$. $(D-F)$ Rpl17 residues that contact helix 2 , helix 24 , and the loop in domain III, respectively. $(G, H)$ Residues of the Rpl17 globular domain facing intact or cropped helix 2, respectively. Images were generated using ICM-Browser (Molsoft). over, we depleted Rpl17 for $7 \mathrm{~d}$ using doxycycline-inducible but not in Rpl10 depletion that does not significantly increase $32 \mathrm{~S}_{\mathrm{C}}$ pre-rRNA (Fig. $3 \mathrm{C}$ ). To further rule out that $5.8 \mathrm{~S}_{\mathrm{C}}$ rRNA is an aberrant species destined for degradation, we separated cytoplasmic extracts on a sucrose gradient. Hybridization analysis revealed the presence of $5.8 \mathrm{~S}_{\mathrm{C}}$ rRNA in polysomal fractions (Fig. 3D), indicating that $60 \mathrm{~S}$ subunits containing this $5^{\prime}$-truncated $5.8 \mathrm{~S}$ form are functional in translation. Finally, we asked whether cells other than the $3 \mathrm{~T} 3 \mathrm{~s}$ analyzed above contain $5.8 \mathrm{~S}_{\mathrm{C}}$ rRNA. Hybridizations showed that the $5.8 \mathrm{~S}_{\mathrm{C}}$ species was present in all tested mouse and human cell lines (Fig. 3E).

Together, these findings provide a strong indication that $32 \mathrm{~S}_{\mathrm{C}}$ pre-rRNA can be processed to $5.8 \mathrm{~S}_{\mathrm{C}}$ rRNA, which gives rise to translationally competent ribosomes. Although the generation of $5.8 \mathrm{~S}_{\mathrm{C}}$ is greatly increased when Rpl17 is limiting, the presence of the $5.8 \mathrm{~S}_{\mathrm{C}}$ rRNA in normal cells indicates that this species is continuously generated in a fraction of $60 \mathrm{~S}$ maturation events. It seems plausible that stochastic variations during assembly of individual subunits may involve delayed loading of Rpl17, leading to occasional Xrn2 overruns when this enzymes trims the $5^{\prime}$ ends of $5.8 \mathrm{~S}$ precursors. Notably, northern hybridizations of yeast 5.8S rRNA do not show detectable "cropped" forms (data not shown). The $5^{\prime}$ heterogeneity of mammalian 5.8S rRNA might thus reflect a less rigid assembly order and/or more relaxed surveillance mechanisms, leading to a greater structural diversity of ribosomes in these species.

\section{Interactions of Rpl17 with full-length and cropped 5.8S rRNA in mature ribosomes}

The $5^{\prime}$ end truncation in $5.8 \mathrm{~S}_{\mathrm{C}}$ rRNA removes a large portion of the evolutionarily conserved helix 2 formed by $5.8 \mathrm{~S}$ and domain I of 28/25S rRNA (Fig. 4A). To obtain insight into possible consequences of this disruption, we looked at the local ribosome environment in a highresolution structure of the mammalian 
ribosome-Sec61 complex (Voorhees et al. 2014). Helix 2 in a mature 60S subunit is positioned in close proximity to Rpl17, which interacts with $28 \mathrm{~S}$ and $5.8 \mathrm{~S}$ rRNAs at several sites (Fig. 4B,C). Rpl17 is comprised of two distinct structural elements: a compact globular domain and an extended $\beta$-hairpin (Zhang et al. 2013). The globular domain extensively interacts with domain I of the $60 \mathrm{~S}$ subunit (Fig. 4C). Specific interactions involve two Rpl17 residues, R62 and Y63, engaged in hydrogen bonding with helix 2 (Fig. 4D), and two asparagine residues (N97, N101) forming hydrogen bonds with nucleotide residues of helix 24 (Fig. 4E). The $\beta$-hairpin extends deep inside the ribosome so that its tip faces the exit tunnel and forms additional hydrophobic/electrostatic contacts with a hairpin loop in domain III of $28 \mathrm{~S}$ rRNA (Fig. 4F; Voorhees et al. 2014). The absence of ten $5^{\prime}$-terminal nucleotides in $5.8 \mathrm{~S}_{\mathrm{C}}$ rRNA destabilizes the interaction of the globular domain of Rpl17 with helix 2 (Fig. 4G,H), likely affecting conformational rearrangements in this r-protein at the subunit surface in the vicinity of the exit tunnel. Interestingly, the globular domain of yeast Rpl17 has been previously shown to be in proximity with Sec61 translocon components; moreover, the presence of a transmembrane segment in the nascent polypeptide chain inside the exit tunnel is sensed by Rpl17 to recruit the small translocon-associated protein RAMP4 (Pool 2009). An altered conformational flexibility of mammalian Rpl17 in $60 \mathrm{~S}$ subunits harboring $5.8 \mathrm{~S}_{\mathrm{C}}$ rRNA may thus impact the interface between the ribosome and the translocon, and potentially other cellular factors interacting with nascent polypeptide chains. Experiments are in progress to address the functional consequences of these changes.

\section{Concluding remarks}

In this study, we analyzed effects of depletion of Rpl17, an integral r-protein of the large ribosomal subunit, in mouse cells. Our results revealed that like its previously studied yeast ortholog, mouse Rpl17 is required for pre-rRNA processing in ITS2. Depletion of Rpl17 also strongly affected processing efficiency at the 5.8S-proximal ITS1 site 2c, similar to several other factors involved in $60 \mathrm{~S}$ subunit maturation in mouse cells (Wang et al. 2014). Interestingly, formation of the short $5.8 \mathrm{~S}$ precursor $32 \mathrm{~S}_{\mathrm{S}}$ in Rpl17-depleted cells was affected to a much greater extent than the long form $32 \mathrm{~S}_{\mathrm{L}}$. Furthermore, depletion of the $5^{\prime}$ exoribonuclease Xrn2, whose yeast homo$\log$ Rat 1 was implicated in the generation of short $5^{\prime}$ ends of 5.8S rRNA, preferentially affected long $5.8 \mathrm{~S}$ precursors in mouse cells. These differences between yeast and mouse cells might reflect distinct kinetics of ITS1 processing or in fact indicate that generation of the long rather than short $5.8 \mathrm{~S}$ species requires a $5^{\prime}$-exonucleolytic activity in mouse cells.

We also found that depletion of mouse Rpl17 promoted the formation of "cropped" $32 S_{\mathrm{C}}$ pre-rRNA. Similar 5'-truncated 28SB forms were observed in yeast as an intermediate in Rat1-mediated turnover of pre-rRNA in stalled pre-60S sub- units (Sahasranaman et al. 2011; Gamalinda et al. 2013). Surprisingly, mammalian $32 \mathrm{~S}_{\mathrm{C}}$ pre-rRNA gives rise to functional ribosomes in a fraction of maturation events. These results indicate that deficiency in assembly components does not always end up with the elimination of ribosomal precursors; moreover, altered ribosome maturation can lead to structural changes in the newly synthesized ribosomes, thus impacting ribosome diversity in the cell. Importantly, changes in mature ribosomes were only observed through experimentally induced long-term r-protein depletion, which allowed sufficient time for turnover of the pre-existing ribosomes. Because many ribosomopathies result from a chronic reduction of r-protein expression in the organism, it is tempting to speculate that slowly occurring changes in ribosome diversity may underlie some of the protein-specific phenotypes observed in these disorders. Heterogeneity of cytoplasmic ribosomes is emerging as an important, yet still poorly understood, mechanism of regulation in gene expression (Xue and Barna 2012). Understanding the functional differences between structurally divergent ribosomes will be an important direction for the future studies. It would also be interesting to see if imbalanced expression of other r-proteins may translate into distinct alterations of rRNA in mature ribosomes.

\section{MATERIALS AND METHODS}

\section{Cell culture and transfections}

Cells were maintained and transfected with siGENOME SMARTpool siRNAs (Dharmacon) as described previously (Shcherbik et al. 2010). Knockdown efficiency of r-proteins was assessed by regular and quantitative RT-PCR (Wang et al. 2014). Transfections that reduced Rpl17 and Rpl10 mRNA levels to $<5 \%$ relative to cells transfected with nontargeting siRNA were used for quantitative pre-rRNA assays. Xrn2 knockdowns were monitored using immunoblotting with antibodies sc-99237 (Santa Cruz) and estimated to provide $60 \%-80 \%$ reduction of Xrn2 protein levels. For shRNA-mediated knockdowns, Rpl17- and Rpl10-specific cassettes were transferred from pGIPZ constructs (Dharmacon) into the doxycycline-inducible pIVRE vector (Wang et al. 2014), the resulting plasmids were transfected into NIH $3 \mathrm{~T} 3$ cells and stable clones were selected with puromycin. Expression of shRNA was induced with $2 \mu \mathrm{g} / \mathrm{mL}$ doxycycline. Because of a slight leakiness of the pIVRE-shRNA constructs, siRNA transfections were used for all quantitative assays. Cell numbers were determined using the CyQUANT cell proliferation assay (Life Technologies).

\section{RNA analysis}

RNA was extracted from cells using RNazol RT (Molecular Research Center, Inc.). Long RNA species were separated using modified formaldehyde-agarose gels (Mansour and Pestov 2013) and hybridized with ${ }^{32} \mathrm{P}$-labeled oligonucleotide probes (Pestov et al. 2008). Steady-state levels of rRNA processing intermediates were determined by phosphorimager analysis, and their ratios analyzed as described (Wang et al. 2014). Primer extensions were carried out 
according to our previously published protocol (Wang and Pestov 2011). Cytoplasmic ribosomes were fractionated using the protocol from Strezoska et al. (2000).

To estimate the fraction of $32 \mathrm{~S}_{\mathrm{L}+\mathrm{S}}$ pre-rRNAs in the $32 \mathrm{~S}$ band (Fig. 2E,F), we hybridized the same membrane sequentially with probes $5.8 \mathrm{~S}-19$ (detects $32 \mathrm{~S}_{\mathrm{L}+\mathrm{S}}$ only) and $5.8 \mathrm{~S}-37$ (detects $32 \mathrm{~S}_{\mathrm{L}+\mathrm{S}+\mathrm{C}}$ ). After each hybridization, the membrane was scanned using a phosphorimager. The total pixel volume $V_{36 S}$ in bands containing $36 \mathrm{~S}$ pre-rRNA, which has the same number of binding sites for both probes, was used to correct for differences between probe labeling and hybridization efficiencies. The normalization coefficient $K_{\text {norm }}$ was defined as the mean of the individual ratios $k=$ $V_{36 \mathrm{~S}, 19} / V_{36 \mathrm{~S}, 37}$ for each $36 \mathrm{~S}$ band on the blot; the coefficient of variation between $k$ values in our experimental set was $<3 \%$. The fraction of $32 \mathrm{~S}_{\mathrm{L}+\mathrm{S}}$ pre-rRNA in each sample was then calculated as $V_{32 \mathrm{~S}, 19} /\left(K_{\text {norm }} \times V_{32 \mathrm{~S}, 37)}\right.$, where $V_{32 \mathrm{~S}, 19}$ and $V_{32 \mathrm{~S}, 37}$ are total pixel volumes obtained for the $32 \mathrm{~S}$ pre-rRNA band with probes $5.8 \mathrm{~S}-19$ and 5.8S-37.

To analyze 5.8S rRNA, $0.25 \mu \mathrm{g}$ total cellular RNA was mixed with loading buffer (95\% formamide, $1 \mathrm{mM}$ EDTA, $0.02 \%$ bromophenol blue and $0.03 \%$ xylene cyanol), heated at $70^{\circ} \mathrm{C}$ for $5 \mathrm{~min}$ and loaded on $0.75 \mathrm{~mm}, 10 \times 10 \mathrm{~cm} 6 \%$ polyacrylamide gels containing $8 \mathrm{M}$ urea and $0.5 \times \mathrm{TBE}$ that were prerun for $15 \mathrm{~min}$ at $250 \mathrm{~V}$. Gels were run at the same voltage in $0.5 \times$ TBE. RNA was transferred to nylon membranes in $0.5 \times$ TBE for $30 \mathrm{~min}$ at $10 \mathrm{~V}$ using a Transblot SD semi-dry apparatus (Bio-Rad).

\section{Gel purification of RNA}

To separate long pre-rRNAs from mature rRNAs, we modified the analytical gel electrophoresis method of Goda and Minton (1995) as follows. A total of $3 \mu \mathrm{g}$ of RNA dissolved in formamide was mixed with an equal volume of $2 \times$ loading buffer ( $80 \mathrm{mM}$ guanidine thiocyanate, $2 \times$ HT buffer $(60 \mathrm{mM}$ HEPES, $60 \mathrm{mM}$ triethanolamine Mansour and Pestov 2013), 2 mM EDTA and 0.08\% bromophenol blue), incubated at $65^{\circ} \mathrm{C}$ for $3 \mathrm{~min}$ and cooled to room temperature. RNA samples were loaded onto $1.2 \%(\mathrm{w} / \mathrm{v})$ agarose gels that were both prepared and run in $1 \times$ HT buffer containing $40 \mathrm{mM}$ guanidine thiocyanate and $0.2 \mu \mathrm{g} / \mathrm{mL}$ ethidium bromide. Separated RNA was visualized under long-wave UV light and the desired bands were cut out from the gel. RNA was isolated from gel slices with the Zymoclean Gel RNA Recovery Kit (Zymo Research) according to the manufacturer's recommendations.

\section{Oligonucleotides}

The sequences of oligonucleotides used in this study are as follows: ITS2-pEx1: GGGGTGGAGGATCTTACTCA; 5.8-19: 5'-GATCCA CCGCTAAGAGTCGT; 5.8-37: 5'-TCGACGCACGAGCCGAGTG AT; 5.8-113: 5'-GCAAGTGCGTTCGAAGTGT. PCR primer sequences are available upon request.

\section{ACKNOWLEDGMENTS}

This work was supported by the National Institute of General Medical Sciences of the National Institutes of Health (NIH) grant GM074091 to D.G.P. and the Foundation of UMDNJ grant to N.S.

Received January 31, 2015; accepted April 10, 2015.

\section{REFERENCES}

Armistead J, Triggs-Raine B. 2014. Diverse diseases from a ubiquitous process: the ribosomopathy paradox. FEBS Lett 588: 1491-1500.

Auger-Buendia MA, Longuet M, Tavitian A. 1979. Kinetic studies on ribosomal proteins assembly in preribosomal particles and ribosomal subunits of mammalian cells. Biochim Biophys Acta 563: $113-128$.

Babiano R, de la Cruz J. 2010. Ribosomal protein L35 is required for $27 \mathrm{SB}$ pre-rRNA processing in Saccharomyces cerevisiae. Nucleic Acids Res 38: 5177-5192.

Babiano R, Gamalinda M, Woolford JL Jr, de la Cruz J. 2012. Saccharomyces cerevisiae ribosomal protein L26 is not essential for ribosome assembly and function. Mol Cell Biol 32: 3228-3241.

Ben-Shem A, Garreau de Loubresse N, Melnikov S, Jenner L, Yusupova G, Yusupov M. 2011. The structure of the eukaryotic ribosome at 3.0 A resolution. Science 334: 1524-1529.

Bowman LH, Rabin B, Schlessinger D. 1981. Multiple ribosomal RNA cleavage pathways in mammalian cells. Nucleic Acids Res 9: 49514966.

Bowman LH, Goldman WE, Goldberg GI, Hebert MB, Schlessinger D. 1983. Location of the initial cleavage sites in mouse pre-rRNA. Mol Cell Biol 3: 1501-1510.

Bursac S, Brdovcak MC, Donati G, Volarevic S. 2014. Activation of the tumor suppressor p53 upon impairment of ribosome biogenesis. Biochim Biophys Acta 1842: 817-830.

Carron C, O’Donohue M-F, Choesmel V, Faubladier M, Gleizes P-E. 2011. Analysis of two human pre-ribosomal factors, bystin and hTsrl, highlights differences in evolution of ribosome biogenesis between yeast and mammals. Nucleic Acids Res 39: 280-291.

Chen SS, Williamson JR. 2013. Characterization of the ribosome biogenesis landscape in $E$. coli using quantitative mass spectrometry. $J$ Mol Biol 425: 767-779.

Dudov KP, Dabeva MD, Hadjiolov AA, Todorov BN. 1978. Processing and migration of ribosomal ribonucleic acids in the nucleolus and nucleoplasm of rat liver nuclei. Biochem J 171: 375-383.

Eisinger DP, Dick FA, Trumpower BL. 1997. Qsrlp, a 60S ribosomal subunit protein, is required for joining of $40 \mathrm{~S}$ and $60 \mathrm{~S}$ subunits. Mol Cell Biol 17: 5136-5145.

El Hage A, Koper M, Kufel J, Tollervey D. 2008. Efficient termination of transcription by RNA polymerase I requires the $5^{\prime}$ exonuclease Rat1 in yeast. Genes Dev 22: 1069-1081.

Ellis SR, Gleizes P-E. 2011. Diamond Blackfan anemia: ribosomal proteins going rogue. Semin Hematol 48: 89-96.

Faber AW, Vos HR, Vos JC, Raué HA. 2006. 5'-end formation of yeast 5.8SL rRNA is an endonucleolytic event. Biochem Biophys Res Commun 345: 796-802.

Ferreira-Cerca S, Pöll G, Kühn H, Neueder A, Jakob S, Tschochner H, Milkereit P. 2007. Analysis of the in vivo assembly pathway of eukaryotic 40S ribosomal proteins. Mol Cell 28: 446-457.

Gamalinda M, Jakovljevic J, Babiano R, Talkish J, de la Cruz J, Woolford JL. 2013. Yeast polypeptide exit tunnel ribosomal proteins L17, L35 and L37 are necessary to recruit late-assembling factors required for 27SB pre-rRNA processing. Nucleic Acids Res 41: 1965-1983.

Gamalinda M, Ohmayer U, Jakovljevic J, Kumcuoglu B, Woolford J, Mbom B, Lin L, Woolford JL. 2014. A hierarchical model for assembly of eukaryotic 60S ribosomal subunit domains. Genes Dev 28: 198-210.

Goda SK, Minton NP. 1995. A simple procedure for gel electrophoresis and Northern blotting of RNA. Nucleic Acids Res 23: 3357-3358.

Hadjiolova KV, Nicoloso M, Mazan S, Hadjiolov AA, Bachellerie J-P. 1993. Alternative pre-rRNA processing pathways in human cells and their alteration by cycloheximide inhibition of protein synthesis. Eur J Biochem 212: 211-215.

Henras AK, Plisson-Chastang C, O’Donohue M-F, Chakraborty A, Gleizes P-E. 2015. An overview of pre-ribosomal RNA processing in eukaryotes. Wiley Interdiscip Rev RNA 6: 225-242. 
Henry Y, Wood H, Morrissey JP, Petfalski E, Kearsey S, Tollervey D. 1994. The $5^{\prime}$ end of yeast $5.8 \mathrm{~S}$ rRNA is generated by exonucleases from an upstream cleavage site. EMBO J 13: 2452-2463.

Horos R, IJspeert H, Pospisilova D, Sendtner R, Andrieu-Soler C, Taskesen E, Nieradka A, Cmejla R, Sendtner M, Touw IP, et al. 2012. Ribosomal deficiencies in Diamond-Blackfan anemia impair translation of transcripts essential for differentiation of murine and human erythroblasts. Blood 119: 262-272.

Jakob S, Ohmayer U, Neueder A, Hierlmeier T, Perez-Fernandez J, Hochmuth E, Deutzmann R, Griesenbeck J, Tschochner H, Milkereit P. 2012. Interrelationships between yeast ribosomal protein assembly events and transient ribosome biogenesis factors interactions in early pre-ribosomes. PLoS One 7: e32552.

Jakovljevic J, Ohmayer U, Gamalinda M, Talkish J, Alexander L, Linnemann J, Milkereit P, Woolford JL. 2012. Ribosomal proteins L7 and L8 function in concert with six A3 assembly factors to propagate assembly of domains I and II of 25S rRNA in yeast 60S ribosomal subunits. RNA 18: 1805-1822.

Kirn-Safran CB, Oristian DS, Focht RJ, Parker SG, Vivian JL, Carson DD. 2007. Global growth deficiencies in mice lacking the ribosomal protein HIP/RPL29. Dev Dyn 236: 447-460.

Kondrashov N, Pusic A, Stumpf CR, Shimizu K, Hsieh AC, Xue S, Ishijima J, Shiroishi T, Barna M. 2011. Ribosome-mediated specificity in Hox mRNA translation and vertebrate tissue patterning. Cell 145: 383-397.

Lapik YR, Fernandes CJ, Lau LF, Pestov DG. 2004. Physical and functional interaction between Pes1 and Bop1 in mammalian ribosome biogenesis. Mol Cell 15: 17-29.

Lastick SM. 1980. The assembly of ribosomes in HeLa cell nucleoli. Eur J Biochem FEBS 113: 175-182.

Ludwig LS, Gazda HT, Eng JC, Eichhorn SW, Thiru P, Ghazvinian R, George TI, Gotlib JR, Beggs AH, Sieff CA, et al. 2014. Altered translation of GATAl in Diamond-Blackfan anemia. Nat Med 20: 748-753.

Mansour FH, Pestov DG. 2013. Separation of long RNA by agaroseformaldehyde gel electrophoresis. Anal Biochem 441: 18-20.

McIntosh KB, Bhattacharya A, Willis IM, Warner JR. 2011. Eukaryotic cells producing ribosomes deficient in Rpl1 are hypersensitive to defects in the ubiquitin-proteasome system. PLoS One 6: e23579.

Moritz M, Paulovich AG, Tsay YF, Woolford JL. 1990. Depletion of yeast ribosomal proteins L16 or rp59 disrupts ribosome assembly. J Cell Biol 111: 2261-2274.

O’Donohue M-F, Choesmel V, Faubladier M, Fichant G, Gleizes P-E. 2010. Functional dichotomy of ribosomal proteins during the synthesis of mammalian $40 \mathrm{~S}$ ribosomal subunits. J Cell Biol 190: 853-866.

Ohmayer U, Gamalinda M, Sauert M, Ossowski J, Pöll G, Linnemann J, Hierlmeier T, Perez-Fernandez J, Kumcuoglu B, Leger-Silvestre I, et al. 2013. Studies on the assembly characteristics of large subunit ribosomal proteins in S. cerevisae. PLoS One 8: e68412.

O'Leary MN, Schreiber KH, Zhang Y, Duc A-CE, Rao S, Hale JS, Academia EC, Shah SR, Morton JF, Holstein CA, et al. 2013. The ribosomal protein Rpl22 controls ribosome composition by directly repressing expression of its own paralog, Rpl2211. PLoS Genet 9: e1003708.

Pestov DG, Lapik YR, Lau LF. 2008. Assays for ribosomal RNA processing and ribosome assembly. Curr Protoc Cell Biol 39: 22.11.1-22.11.16.

Pöll G, Braun T, Jakovljevic J, Neueder A, Jakob S, Woolford JL, Tschochner H, Milkereit P. 2009. rRNA maturation in yeast cells depleted of large ribosomal subunit proteins. PLoS One 4: e8249.

Pool MR. 2009. A trans-membrane segment inside the ribosome exit tunnel triggers RAMP4 recruitment to the Sec61p translocase. J Cell Biol 185: 889-902.

Preti M, O’Donohue M-F, Montel-Lehry N, Bortolin-Cavaille M-L, Choesmel V, Gleizes P-E. 2013. Gradual processing of the ITS1 from the nucleolus to the cytoplasm during synthesis of the human 18S rRNA. Nucleic Acids Res 41: 4709-4723.

Raiser DM, Narla A, Ebert BL. 2014. The emerging importance of ribosomal dysfunction in the pathogenesis of hematologic disorders. Leuk Lymphoma 55: 491-500.

Robledo S, Idol RA, Crimmins DL, Ladenson JH, Mason PJ, Bessler M. 2008. The role of human ribosomal proteins in the maturation of rRNA and ribosome production. RNA 14: 1918-1929.

Rubin GM. 1974. Three forms of the 5.8-S ribosomal RNA species in Saccharomyces cerevisiae. Eur J Biochem FEBS 41: 197-202.

Sahasranaman A, Dembowski J, Strahler J, Andrews P, Maddock J, Woolford JL. 2011. Assembly of Saccharomyces cerevisiae 60S ribosomal subunits: role of factors required for $27 \mathrm{~S}$ pre-rRNA processing. EMBO J 30: 4020-4032.

Saveanu C, Namane A, Gleizes P-E, Lebreton A, Rousselle J-C, NoaillacDepeyre J, Gas N, Jacquier A, Fromont-Racine M. 2003. Sequential protein association with nascent $60 \mathrm{~S}$ ribosomal particles. Mol Cell Biol 23: 4449-4460.

Savino R, Gerbi SA. 1990. In vivo disruption of Xenopus U3 snRNA affects ribosomal RNA processing. EMBO J 9: 2299-2308.

Shcherbik N, Wang M, Lapik YR, Srivastava L, Pestov DG. 2010. Polyadenylation and degradation of incomplete RNA polymerase I transcripts in mammalian cells. EMBO Rep 11: 106-111.

Sloan KE, Mattijssen S, Lebaron S, Tollervey D, Pruijn GJM, Watkins NJ. 2013. Both endonucleolytic and exonucleolytic cleavage mediate ITS1 removal during human ribosomal RNA processing. $J$ Cell Biol 200: 577-588.

Smith SD, Banerjee N, Sitz TO. 1984. Gene heterogeneity: a basis for alternative 5.8S rRNA processing. Biochemistry 23: 3648-3652.

Steffen KK, McCormick MA, Pham KM, MacKay VL, Delaney JR, Murakami CJ, Kaeberlein M, Kennedy BK. 2012. Ribosome deficiency protects against ER stress in Saccharomyces cerevisiae. Genetics 191: 107-118.

Strezoska Z, Pestov DG, Lau LF. 2000. Bop1 is a mouse WD40 repeat nucleolar protein involved in $28 \mathrm{~S}$ and $5.8 \mathrm{~S}$ rRNA processing and $60 \mathrm{~S}$ ribosome biogenesis. Mol Cell Biol 20: 5516-5528.

Teng T, Mercer CA, Hexley P, Thomas G, Fumagalli S. 2013. Loss of tumor suppressor RPL5/RPL11 does not induce cell cycle arrest but impedes proliferation due to reduced ribosome content and translation capacity. Mol Cell Biol 33: 4660-4671.

Thapa M, Bommakanti A, Shamsuzzaman M, Gregory B, Samsel L, Zengel JM, Lindahl L. 2013. Repressed synthesis of ribosomal proteins generates protein-specific cell cycle and morphological phenotypes. Mol Biol Cell 24: 3620-3633.

Todorov IT, Noll F, Hadjiolov AA. 1983. The sequential addition of ribosomal proteins during the formation of the small ribosomal subunit in friend erythroleukemia cells. Eur J Biochem 131: 271-275.

Voorhees RM, Fernández IS, Scheres SHW, Hegde RS. 2014. Structure of the mammalian ribosome-Sec61 complex to $3.4 \AA$ A resolution. Cell 157: 1632-1643.

Wang M, Pestov DG. 2011. 5'-end surveillance by Xrn2 acts as a shared mechanism for mammalian pre-rRNA maturation and decay. Nucleic Acids Res 39: 1811-1822.

Wang M, Anikin L, Pestov DG. 2014. Two orthogonal cleavages separate subunit RNAs in mouse ribosome biogenesis. Nucleic Acids Res 42: 11180-11191.

West M, Hedges JB, Chen A, Johnson AW. 2005. Defining the order in which Nmd3p and Rpl10p load onto nascent 60S ribosomal subunits. Mol Cell Biol 25: 3802-3813.

Woolford JL, Baserga SJ. 2013. Ribosome biogenesis in the yeast Saccharomyces cerevisiae. Genetics 195: 643-681.

Xue S, Barna M. 2012. Specialized ribosomes: a new frontier in gene regulation and organismal biology. Nat Rev Mol Cell Biol 13: 355-369.

Zhang Y, Wölfle T, Rospert S. 2013. Interaction of nascent chains with the ribosomal tunnel proteins Rpl4, Rpl17, and Rpl39 of Saccharomyces cerevisiae. J Biol Chem 288: 33697-33707. 

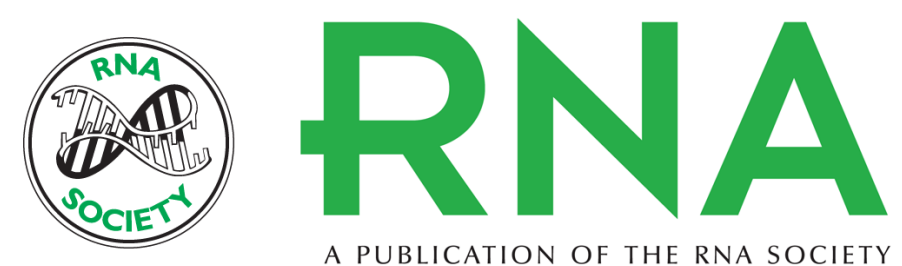

A PUBLICATION OF THE RNA SOCIETY

\section{Reduced expression of the mouse ribosomal protein Rpl17 alters the diversity of mature ribosomes by enhancing production of shortened 5.8S rRNA}

Minshi Wang, Andrey V. Parshin, Natalia Shcherbik, et al.

RNA $201521: 1240-1248$ originally published online May 20, 2015

Access the most recent version at doi:10.1261/rna.051169.115

References This article cites 61 articles, 24 of which can be accessed free at: http://rnajournal.cshlp.org/content/21/7/1240.full.html\#ref-list-1

Creative This article is distributed exclusively by the RNA Society for the first 12 months after the Commons

License full-issue publication date (see http://rnajournal.cshlp.org/site/misc/terms.xhtml). After 12 months, it is available under a Creative Commons License (Attribution-NonCommercial 4.0 International), as described at http://creativecommons.org/licenses/by-nc/4.0/.

Email Alerting
Service

Receive free email alerts when new articles cite this article - sign up in the box at the top right corner of the article or click here. 